\title{
Strategi Pengembangan Ekowisata Pantai Sariah, Kelurahan Pakis, Kecamatan Banyuwangi, Kabupaten Banyuwangi
}

\section{Sariah Beach Ecotourism Development Strategy, Pakis Village, Banyuwangi District, Banyuwangi Regency Kabupaten}

\author{
Mega Yuniartik1*, Agustina Tri Kusuma Dewi2, Magdalena Putri Nugrahani3 \\ 1,2Program Studi Ilmu Perikanan, Universitas 17 Agustus 1945 Banyuwangi, Jalan Adi Sucipto No. 26, \\ Banyuwangi, Jawa Timur, Indonesia. \\ 3Program Studi Pendidikan Biologi, Universitas 17 Agustus 1945 Banyuwangi, Jalan Adi Sucipto No. \\ 26, Banyuwangi, Jawa Timur, Indonesia \\ *Correspondent Author : megayuniartik@untag-banyuwangi.ac.id
}

Submited: 30 June 2021 Revised: 09 July 2021 Accepted : 14 July 2021 Publish : 31 July 2021

\begin{abstract}
Abstrak
Pantai Sariah merupakan salah satu potensi ekowisata yang berada di kelurahan Pakis, Banyuwangi dengan karateristik pasir hitam, vegetasi mangrove sejati dan asosiasi, pohon cemara. Penelitian ini bertujuan menentukan pengembangan ekowisata berbasis komunitas dan sumberdaya alam. Metode penelitian menggunakan deskriptif kuantitatif Focus Group Discussion (FGD), untuk menentukan IFAS dan EFAS. Analisis data menggunakan analisis SWOT. Hasil penelitian menunjukkan alternatif strategi pengembangan ekowisata yang meliputi Peningkatan pengetahuan dan teknologi pada masyarakat berbasis sumberdaya, perbaikan sarana dan prasarana penunjang, pengelolaan ekowisata berbasis mangrove, keragaman avifauna, dan penjagaan konservasi penyu. Selanjutnyam, integrasi kepentingan yang melibatkan stake holder di pantai Sari.

Kata kunci: ekowisata, mangrove, pengembangan, Pantai Sari,ah
\end{abstract}

\section{Abstract}

Sariah Beach is one of the ecotourism potentials located in the village of Pakis, Banyuwangi with the characteristics of black sand, true mangrove vegetation, and associations, pine trees. This study aims to determine the development of community-based ecotourism and natural resources. The research method uses descriptive quantitative Focus Group Discussion (FGD), to determine IFAS and EFAS. Data analysis using SWOT analysis. The results showed alternative ecotourism development strategies which included increasing knowledge and technology in resource-based communities, improving supporting facilities and infrastructure, managing mangrove-based ecotourism, avifauna diversity, and maintaining turtle conservation. Furthermore, the integration of interests involving stakeholders at Sari beach.

Keywords: ecotourism, mangrove, development, Sariah Beach 


\section{PENDAHULUAN}

$\begin{array}{rrr}\text { Salah } & \text { satu arah kebijakan } \\ \text { pembangunan } & \text { perikanan } & \text { adalah }\end{array}$
pengelolaan wilayah laut, pesisir dan pulau-pulau kecil, serta penguatan pengawasan sumber daya kelautan dan perikanan. Strategi untuk mencapai hal tersebut adalah melalui peningkatan manajemen dan pemanfaatan kawasan konservasi perairan secara berkelanjutan (Renstra KKP Tahun 2020 - 2024,). Salah satu ekosistem unik yang menempati wiayah pesisir adalah ekosistem mangrove (Muhammad, 2012). Mangrove merupakan salah satu kawasan konservasi yang terus diperhatikan setiap pemanfaatannya. Ekosistem mangrove merupakan ekosistem yang sangat unik karena memiliki salinitas yang tinggi dan kondisi perairan yang mudah berubah (Muhammad, 2012; Sulastini, 2011). Pantai Sari merupakan salah satu pantai yang termasuk dalam hutan kota Banyuwangi, dengan luas 14,7 Ha dan memiliki panjang pantai 14,7 Ha (Yuniartik et al., 2021). Pantai ini berbatasan dengan lokasi wisata Pantai Cemara di sebelah selatan (Dewi \& Yuniartik, 2019). Salah satu potensi yang dimiliki oleh Pantai Sari adalah ekosistem mangrove. Terdapat 7 jenis mangrove di area sungai dan 5 spesies lainnya di wilayah pesisir, serta terdapat 11 jenis mangrove asosiasi (Yuniartik et al., 2021).

Selain potensi tersebut, terdapat juga beberapa spesies avifauna, lokasi pendaratan penyu, dan juga terdapat aktivitas penangkapan ikan oleh kelompok nelayan Pantai Sari. Namun, potensi tersebut belum dapat dikelola secara optimal sebagai kawasan ekowisata oleh kelompok nelayan pantai Sari,ah. Sehingga perlu dilakukan suatu kajian untuk dapat memecahkan permasalahan yang terjadi tersebut. Berdasarkan latar belakang di atas, tujuan penelitian ini adalah untuk mengetahui strategi pengembangan ekowisata berdasarkan potensi dan di Pantai Sari, Kelurahan Pakis, Banyuwangi.

\section{METODE PENELITIAN}

\section{Waktu dan lokasi penelitian}

Penelitian ini dilakukan di panati Sari kelurahan Pakis Banyuwangi, pada bulan Juni sampai Agustus 2019 (Gambar 1). 


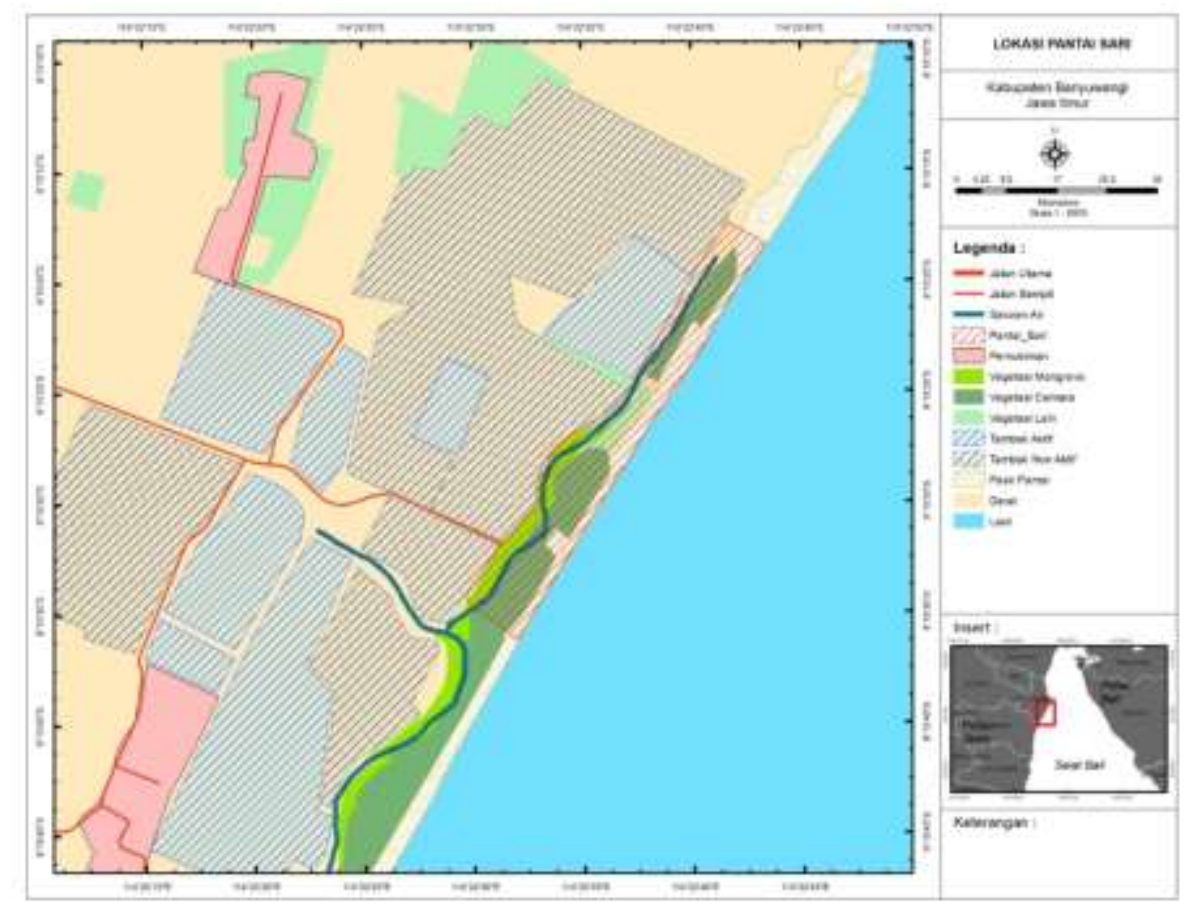

Gambar 1. Lokasi penelitian

\section{Metode pengumpulan data}

Metode pengumpulan data penelitian digunakan 2 sumber data yaitu data primer dan data sekunder. Data primer merupakan data yang diperoleh langsung dari sumbernya melalui Focus Group Discussion (FGD) yang dilakukan oleh kelompok nelayan Pantai Sari dan stakeholder terkait. Selanjutnya data sekunder diperoleh melalui studi pustaka dan laporanlaporan yang diperoleh dari instansi terkait.

\section{Analisis data}

Analisis data yang digunakan yaitu dengan menggunakan analisis SWOT. Analisis SWOT didahului dengan pembuatan matriks Internal Strategic Factor Analysis Summary (IFAS) dan External Strategic Factor Analysis Summary (EFAS). Penyusunan matriks IFAS dan EFAS didasarkan pada hasil analisis terhadap sistem, yaitu dengan melihat faktorfaktor yang menjadi kekuatan dan kelemahan internal, serta peluang dan ancaman eksternal (Hunger \& Wheelen, 2003). Pembobotan pada masingmasing faktor mulai dari 1,00 (sangat penting) sampai dengan 0,00 (tidak penting). Skor jumlah bobot keseluruhan factor adalah 1,00. Penentuan rating berdasarkan pengaruh permasalahan. Nilai rating dari 4 (outstanding) sampai dengan 1 (poor). 
Pemberian nilai rating untuk kekuatan bersifat positif (semakin besar kekuatan semakin besar pula nilai rating yang diberikan), sedangkan untuk kelemahan dilakukan sebaliknya. Matriks SWOT menggambarkan secara jelas bagaimana peluang dan ancaman eksternal yang dihadapi serta dapat disesuaikan dengan kekuatan dan kelemahan yang dimiliki, dari matriks ini akan terbentuk empat kemungkinan alternatif strategi.

\section{HASIL DAN PEMBAHASAN}

Berdasarkan hasil identifikasi terhadap faktor-faktor internal, maka disusun matriks IFAS kekuatan (strength) (Tabel 1) dan kelemahan (weakness) (Tabel 2). Faktor Internal dalam pengembangan ekowisata Pantai Sari merupakan faktor kekuatan dan kelemahan yang dimiliki oleh kelompok pantai Sari,ah sendiri. Faktor internal pada aspek kekuatan memiliki nilai tertimbang 3,775, sedangkan faktor kelemahan memiliki nilai tertimbang 3,125 .

Tabel 1. Matriks IFAS-Kekuatan (Strenght)

\begin{tabular}{rlrrr}
\hline No. & Variabel Kekuatan (Strenghts) & Bobot & Rating & Skor \\
\hline & Keragaman jenis ikan hasil tangkapan, terutama yang & & & \\
1 & bernilai ekonomis penting & 0,15 & 3 & 0,45 \\
2 & Memiliki pantai cemara yang teduh & 0,175 & 4 & 0,7 \\
3 & Keragaman jenis mangrove sejati dan asosiasi & 0,175 & 4 & 0,7 \\
4 & Keragaman jenis avifauna yang ada di wilayah Pantai Sari & 0,25 & 4 & 1 \\
& Wilayah dengan lokasi pandan laut merupakan lokasi & & & \\
5 & bertelur penyu & 0,175 & 4 & 0,7 \\
6 & Hasil tangkapan kerang di pesisir pantai & 0,075 & 3 & 0,225 \\
\hline & Total Skor Kekuatan (Strenghts) & 1,00 & & 3,775 \\
\hline
\end{tabular}

Tabel 2. Matriks IFAS-Kelemahan (Weakness)

\begin{tabular}{rlrrr}
\hline No. & Variabel Kelemahan (Weakness) & Bobot & \multicolumn{1}{c}{ Rating } & \multicolumn{1}{l}{ Skor } \\
\hline 1 & Akses jalan masuk Pantai Sari sempit dan rusak & 0,1 & -4 & $-0,4$ \\
2 & Jembatan untuk masuk ke wilayah pantai rusak & 0,125 & -4 & $-0,5$ \\
& Sarana dan prasarana yang tidak memadai (mushola dan & & & \\
3 & lahan parkir yang sempit) & -3 & $-0,3$ \\
& Belum ada lokasi tempat berjualan makanan di area & & & \\
4 & Pantai Sari & 0,15 & -3 & $-0,45$ \\
5 & $\begin{array}{l}\text { Perlu modal untuk pengembangan usaha } \\
\text { Belum terintegrasi kepentingan masyarakat Pantai Sari }\end{array}$ & 0,125 & -3 & $-0,375$ \\
& dan sekitarnya, sehingga masih ada warga yang tidak & & \\
6 & peduli terhadap pengembangan kawasan Pantai Sari. & 0,15 & -4 & $-0,6$ \\
& Terdapat tempat pendaratan ikan, tapi kurang memenuhi & & & \\
7 & standart & 0,125 & -3 & $-0,375$ \\
8 & Tutupan mangrove di sebelah utara masih jarang & 0,125 & -1 & $-0,125$ \\
\hline & Total Skor Kelemahan (Weakness) & 1,00 & $-3,125$ \\
\hline
\end{tabular}


Matriks EFAS terdiri dari peluang (Opportunities) (Tabel 3) dan Ancaman (Threats) (Tabel 4). Faktor eksternal dalam pengembangan ekowisata Pantai Sari merupakan faktor peluang dan ancaman dari potensi dan Tabel 3. Matriks EFAS- Variabel peluang (Opportunities)

\begin{tabular}{|c|c|c|c|c|}
\hline No. & Variabel Peluang (Opportunitiy) & Bobot & Rating & Skor \\
\hline 1 & $\begin{array}{l}\text { Kawasan konservasi pendaratan penyu di bagian } \\
\text { pandan laut }\end{array}$ & 0,125 & 3 & 0,375 \\
\hline 2 & Wisata kuliner daerah & 0,1 & 4 & 0,4 \\
\hline 3 & $\begin{array}{l}\text { Pengembangan kawasan wisata tracking di hutan } \\
\text { cemara } \\
\text { Integrasi pengembangan ekowisata dengan Pantai }\end{array}$ & 0,1 & 3 & 0,3 \\
\hline 4 & Cemara (paket wisata) & 0,125 & 3 & 0,375 \\
\hline 5 & $\begin{array}{l}\text { Wisata pancing (fasilitas untuk pemancing } \\
\text { melakukan aktivitas di laut) }\end{array}$ & 0,100 & 2 & 0,2 \\
\hline 6 & $\begin{array}{l}\text { Pengembangan pasar hasil tangkapan ikan segar } \\
\text { Wilayah di sebelah utara dapat digunakan sebagai }\end{array}$ & 0,125 & 4 & 0,5 \\
\hline 7 & $\begin{array}{l}\text { lokasi perkemahan } \\
\text { Dibentuk koperasi untuk kelompok masyarakat }\end{array}$ & 0,125 & 4 & 0,5 \\
\hline 8 & Pantai Sari & 0,1 & 3 & 0,3 \\
\hline 9 & Atraksi avifauna pada saat pagi dan sore hari & 0,10 & 3 & 0,3 \\
\hline & Total Skor Peluang (Opportunities) & 1,00 & & 3,25 \\
\hline
\end{tabular}

Tabel 4. Matriks EFAS- Variabel Ancaman (Threats)

\begin{tabular}{rlrrr}
\hline No. & Variabel Ancaman (Threats) & Bobot & Rating & Skor \\
\hline & Sampah yang bertumpukan di tepi pantai dari bawaan & & & \\
1 & saat proses penangkapan & 0,2 & -4 & $-0,8$ \\
2 & Tambak tidak terpakai di sekitar lokasi jalan masuk & 0,15 & -2 & $-0,3$ \\
3 & Limbah tambak & 0,125 & -2 & $-0,25$ \\
4 & 0,185 & -3 & $-0,555$ \\
& Banjir dan abrasi pesisir di muara sungai & & \\
Terpecahnya kepentingan kelompok masyarakat & & & \\
$\quad$ karena tidak ada integrasi kepentingan di semua & 0,185 & -1 & $-0,185$ \\
5 & elemen masyarakat & & \\
& Kegiatan konservasi cemara dan mangrove terkendala & & $-2,15$ & $-0,3$ \\
6 & dana operasional & 1,00 & & $-2,09$ \\
\hline
\end{tabular}




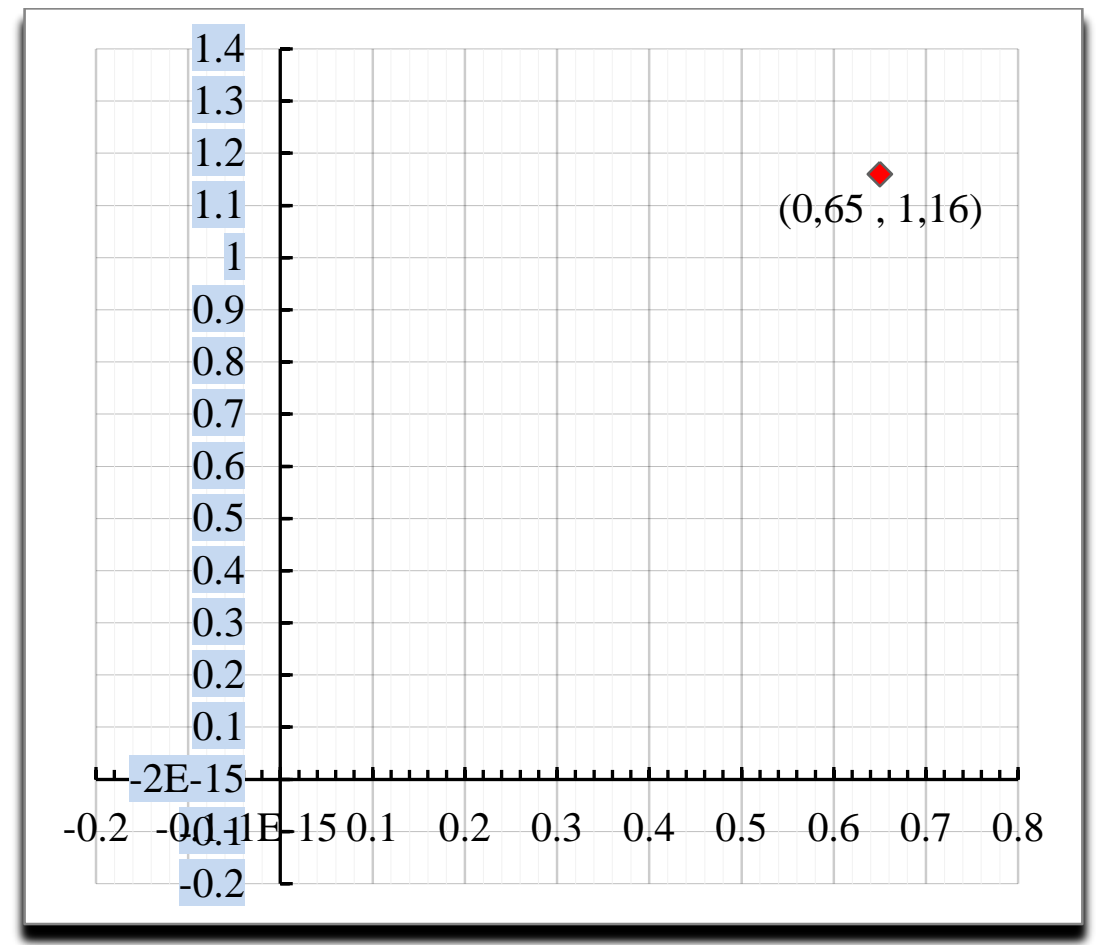

Gambar 2.Kuadran Analisis SWOT

Berdasarkan perhitungan skor dari faktor internal (IFAS) dan faktor eksternal (EFAS) digunakan untuk mengetahui titik koordinat strategi. Faktor internal sebagai sumbu (x), dan faktor eksternal sebagai sumbu (y). Koordinat grand strategy yaitu $(0,65$, 1,16) berada di kuadran I (Gambar 2). Berdasakan matriks tersebut dapat kita ketahui bahwa pengembangan di Pantai Sari Banyuwangi mempunyai peluang dan kekuatan, sehingga strategi yang dikembangkan mampu berperan dalam model. Apabila faktor internal dan eksternal berada di kuadran I, merupakan kondisi yang mendukung kebijakan pertumbuhan yang agresif (Rumengan et al., 2013; Setyaningrum et al., 2019; Setyaningrum et al., 2019). Hal ini didukung juga dengan potensi sumberdaya alam dari Pantai Sari, yaitu potensi mangrove, fauna, dan hasil tangkapan. 
Journal of Aquaculture Science

DOI: https://doi.org/10.31093/joas.v6i1IS.186

Peluang

(Opportunities)

$\mathbf{O}$

Rekomendasi SO:

Peningkatan pengetahuan dan

teknologi pada kelompok masyarakat

berbasis sumberdaya untuk

meningkatkan nilai tambah

dari wilayah ekowisata
Rekomendasi WO:

Perbaikan sarana dan prasarana penunjang kegiatan ekowisata

\section{Ancaman (Threats) \\ T \\ Rekomendasi ST: \\ Pengelolaan ekowisata berbasis mangrove, keragaman avifauna, dan penjagaan konservasi penyu}

\section{Rekomendasi WT:}

Integrasi kepentingan yang melibatkan stakeholder di Pantai Sari.

\section{Berdasarkan Tabel 5 tentang} alternatif strategi dalam pengembangan Pantai Sari, maka rekomendasi yang diberikan sebagai berikut:

\section{Peningkatan pengetahuan dan teknologi} pada kelompok masyarakat berbasis sumberdaya untuk meningkatkan nilai tambah dari wilayah ekowisata;

Peningkatan pengetahuan dan teknologi pada kelompok masyarakat dapat dilakukan dengan memberikan berbagai pelatihan. Pelatihan yang dilakukan yaitu sebagai berikut:

- Pelatihan tour guide $\rightarrow$ Dinas Kebudayaan dan Pariwisata;

- Pelatihan pengolahan produk berbahan sumberdaya lokal, seperti mangrove dan ikan $\rightarrow$

Dinas Perikanan dan Pangan. Selain dari pemerintah, kegiatan pelatihan juga bisa difasilitasi melalui kerjasama dengan perguruan tinggi. Peningkatan pengetahuan kelompok masyarakat merupakan dasar dalam pengembangan ekowisata berbasis masyarakat, sehingga kelompok memiliki peningkatan kemampuan dalam mengelola ekowisata. Pengelolaan ini akan meningkatkan juga daya tarik wisata ke lokasi tersebut. Hal tersebut sejalan dengan pernyataan Karlina (2015), bahwa penawaran produk ekowisata harus diimbangi dengan peningkatan kemampuan dan keterampilan pengelola ekowisata, agar daya tarik wisata semakin meningkat. Selain itu,peningkatan keterampilan kelompok juga harus diimbangi dengan pengetahuan dalam menjaga keberlanjutan dari potensi sumberdaya yang dimiliki di Pantai Sari.

Perbaikan sarana dan prasarana penunjang kegiatan ekowisata; 
Sarana dan prasarana merupakan hal penting yang harus dilengkapi dalam pengembangan ekowisata. Rekomendasi perbaikan sarana dan prasarana penunjang kegiatan ekowisata yang dilakukan sebagai berikut:

Akses jalan dari arah pertigaan Pantai Cemara sampai ke wilayah Pantai Sari perlu dilakukan perbaikan dan pelebaran. Perlu adanya komunikasi lebih lanjut dengan pemilik tambak di sekitar jalan masuk tersebut $\rightarrow$ Dinas Pekerjaan Umum

- Perbaikan jembatan untuk jalan masuk sebelah selatan $\rightarrow$ Dinas Pekerjaan Umum

- Pembangunan Tempat Pendaratan Ikan yang memenuhi standart $\rightarrow$ Dinas Perikanan dan Pangan

- Sarana pondok-pondok sebagai tempat wisata kuliner daerah $\rightarrow$ Masyarakat dan Dinas Perikanan dan Pangan

- $\quad$ Fasilitas penunjang berupa tempat bermain bagi anak-anak, misal tempat bermain pasir dan ayunan $\rightarrow$ Masyarakat dan Kelurahan Pakis

- Mushola untuk tempat beribadah $\rightarrow$ Masyarakat dan Kelurahan Pakis
Sarana dan prasarana yang baik akan mendukung sistem ekowisata dan meningkatkan jumlah pengunjung yang datang ke pantai Sari. Terutama fasilitas kemudahan dan kenyamanan selama berwisata di lokasi Pantai Sari. Hal ini sejalan dengan penelitian yang dilakukanoleh Karlina (2015), bahwa pengunjung tidak hanya tertarik pada kualitas ekowisata, namun juga pada kualitas sarana dan prasarana, mulai berangkat dari tempat asal pengunjung menunju lokasi ekowisata, selama berwisata pengunjung mendapatkan kepuasan dan kemudahan. Peningkatan sarana dan prasarana juga dapat meningkatkan nilai estetika dan ketertiban lokasi ekowisata. Hal tersebut tercipta dikarenakan kondisi sarana dan prasarana untuk berwisata tersedia, sehingga akan meminimalisir dampak sampah yang terjadi. Menyatakan bahwa perbaikan sarana dan prasaran dapat mengatasi perilaku vandalism dan sampah dari wisatawan (Rumengan et al., 2013).

Pengelolaan ekowisata berbasis mangrove, keragaman avifauna, dan penjagaan konservasi penyu

Pengelolaan ekowisata dapat dilakukan sebagai berikut: 
- Pelatihan ekowisata berbasis konservasi $\rightarrow$ Balai Besar Konservasi Sumber

- Daya Alam Seksi Konservasi Wilayah V Banyuwangi

- Pelatihan penanganan dan pemanfaatan sampah $\rightarrow$ Dinas Lingkungan Hidup

- Pemberian batas pada kawasan pendaratan penyu $\rightarrow$ Masyarakat

Pengelolaan ekowisata perlu dilakukan untuk menciptakan suatu ekowisata yang berkelanjutan. Pemanfaatan sumberdaya alam didasarkan pada kaidah yang secukupnya, tanpa menggunakan secara berlebihan, sesuai dengan dasar ekowisata. Benur \& Bramwell (2015), menyatakan prinsip ekowisata, yaitu kegiatan wisata dilakukan dengan tetap memberikan perlindungan kepada lingkungan, mempromosikan kegiatan konservasi serta memberikan dampak positif bagi masyarakat.

\section{Integrasi kepentingan yang melibatkan stakeholder di Pantai} Sari.

Integrasi kepentingan yang melibatkan stakeholder di Pantai Sari sebagai berikut:
- Penyatuan lokasi telusur sungai dengan Pantai Cemara, sehingga perlu adanya pelebaran lokasi sungai di batas sebelah selatan $\rightarrow$ Dinas Pekerjaan Umum

Penambahan paket wisata dengan Pantai Cemara $\rightarrow$ Dinas Perikanan dan Pangan dan KUB Pantai Cemara

Integrasi kepentingan di dalam pengembangan ekowisata merupakan bagian diversifikasi produk ekowisata yang dapat digunakan untuk menarik minat pengunjung. Semakin banyak pilihan atraksi yang ditawarkan di dalam suatu ekowisata, maka ini menarik pengunjung wisata dari semua lapisan masyarakat. Hal ini ditekankan oleh Benur \& Bramwell (2015) bahwa, diversifikasi, intensifikasi, dan keterkaitan produk-produk ini dapat menjadi sangat penting untuk daya saing dan pengembangan tujuan yang berkelanjutan.

\section{KESIMPULAN}

Posisi strategis pengembangan di Pantai Sari Banyuwangi berada pada kuadran I, yaitu mempunyai peluang dan kekuatan, sehingga strategi yang dikembangkan mampu berperan dalam model. Alternatif strategi 
Journal of Aquaculture Science

DOI: https://doi.org/10.31093/joas.v6i1IS.186
July 2021 Vol 6 Issue Spesial: 268-277

Online pada http://joas.co.id

pengembangan ekowisata yaitu: 1).

Peningkatan pengetahuan dan teknologi

pada masyarakat berbasis sumberdaya

untuk meningkatkan nilai tambah dari

wilayah ekowisata; 2). Perbaikan sarana

dan prasarana penunjang kegiatan

ekowisata; 3). Pengelolaan ekowisata

berbasis mangrove, keragaman

avifauna, dan penjagaan konservasi

penyu; 4). Integrasi kepentingan yang

melibatkan stakeholder di Pantai Sari.

\section{Ucapan Terima Kasih}

Kami mengucapkan terimakasih kepada Pemerintah Kabupaten Banyuwangi melalui Badan Pembangunan Daerah Banyuwangi pada Hibah Kompetitif Tahun 2019 yang telah mendanai penelitian ini.

\section{DAFTAR PUSTAKA}

Benur, A. M., \& Bramwell, B. (2015). Tourism product development and product diversification in destinations. Tourism Management, 50, 213-224.

Dewi, A. T. K., \& Yuniartik, M. (2019). Potensi Pantai Cemara, Kabupaten Banyuwangi, Jawa Timur Sebagai Kawasan Ekowisata. JFMR-Journal of Fisheries and Marine Research, 3(3): 351-358.

Hunger, J. D., \& Wheelen, T. L. (2003). Manajemen Strategis. ANDI.

Karlina, E. (2015). Strategi Pengembangan Ekowisata Mangrove Di Kawasan Pantai
Tanjung Bara, Kutai Timur , Kalimatan Timur. Jurnal Penelitian Hutan Dan Konservasi Alam, 12(2): 191-208.

Muhammad, F. (2012). Model Ekowisata Kawasan Hutan Mangrove Berbasis Daya Dukung Fisik Kawasan Dan Resiliensi Ekologi (Kasus Ekowisata Mangrove Blanakan, Subang, Jawa Barat). Institut Pertanian Bogor.

Peraturan Menteri Kelautan dan Perikanan Nomor 17/PERMEN-KP/2020/tentang Rencana Strategis Kementerian Kelautan dan Perikanan Tahun 2020-2024, Pub. L. No. PERMEN-KP/2020 (2020).

Rumengan, S., Achmad, A., \& Oka, N. P. (2013). Strategi Pengambangan Ekowisata di Kelurahan Lemo dan Sarira Kec. Makale Utara Kab. Tana Toraja. 115.

Setyaningrum, E. W., Dewi, A. T. K., Prapti, K. P., Erwanto, Z., \& Susanti, H. D. (2019). Area development based on conservation and ecotourism on the Cemara Beach (Pine Trees Beach), Pakis, Banyuwangi, East Java Province, Indonesia. IOP Conference Series: Earth and Environmental Science, 236(1).

Setyaningrum, Ervina W, Erwanto, Z., Prapti, K. P., Yuniartik, M., \& Dewi, A. T. K. (2019). Ecotourism Development And Its Effect On Alternative Livelihoods In The Cemara Beach of Banyuwangi District. 1(2): 18-25.

Sulastini, D. (2011). Seri Buku Informasi dan Potensi Mangrove Taman Nasional Alas Purwo. In Balai Taman Nasional Alas Purwo. Bayuwangi. Balai Taman Nasional Alas Purwo.

Yuniartik, M., Dewi, A. T. K., Nugrahani, M. P., \& Setyaningrum, E. W. (2021). Identification of The Potential of Mangrove At Pantai Sari, Pakis, Banyuwangi , Java Province. Sriwijaya Journal of Environment, 6(1):36-41. 
Journal of Aquaculture Science

DOI: https://doi.org/10.31093/joas.v6i1IS.186
July 2021 Vol 6 Issue Spesial: 268-277

Online pada http://joas.co.id 